\title{
THE EFFECT OF THE SUPINE POSITION ON RENAL FUNCTION IN THE NEAR-TERM PREGNANT WOMAN 1,2
}

\author{
BY JACK A. PRITCHARD, ALLAN C. BARNES, AND RICHARD H. BRIGHT
}

\author{
(From the Department of Obstetrics and Gymecology, School of Medicine, Western Reserve \\ University and University Hospitals, Cleveland, Ohio)
}

(Submitted for publication December 13, 1954; accepted February 2, 1955)

It has been demonstrated previously that urine flow in the recumbent near-term pregnant woman is appreciably less when she is lying on her back than when she is lying on her side and that without change of position the relative oliguria persists for several hours before it is overcome $(1,2)$.

The present report extends the observations on the effect of position on urine flow to include studies of sodium and potassium excretion, effective renal plasma flow, and glomerular filtration rate in near-term normal pregnant women, in women with eclamptogenic toxemia of pregnancy, and in women with large abdominal neoplasms originating in the pelvis. Attempts have been made to determine the mechanism by which the various observed changes in renal function are produced.

\section{METHODS}

Studies were made 11 times in 10 near-term normally pregnant women and 13 times in 8 women with preeclampsia. In most of these studies the excretion of sodium and potassium, the effective renal plasma flow (RPF) and the glomerular filtration rate (GFR) were measured. In one normal and one preeclamptic pregnant woman the observations were repeated following the insertion of large-bore heavy-walled ureteral catheters into both ureters well above the level of the pelvic brim. Similar renal function studies were made in two women who had large abdominal neoplasms arising from the pelvis, one an ovarian serous cystadenocarcinoma and the other a uterus containing multiple fibromyomas. Both tumors were approximately the size of a uterus at 32 to 34 weeks' gestation. Seven patients who had either delivered 7 or 8 days previously or who had undergone total hysterectomy 9 or 10 days before were also observed. Three subjects of this group had been studied previously while pregnant.

All medications were stopped the night before; 2 hours before starting the study, a breakfast of milk, cereal, and

\footnotetext{
1 This study was assisted by a grant from the Cleveland Area Heart Society.

2 Presented in part at the Fortieth Annual Clinical Congress of the American College of Surgeons, Atlantic City, N. J., November 16, 1954.
}

toast was allowed. One-half hour later an indwelling catheter was inserted into the bladder and oral hydration consisting of $100 \mathrm{ml}$. of water every 20 minutes was initiated. At this time in the 17 studies where effective renal plasma flow and inulin clearances were to be measured sodium paraminohippurate and inulin were given intravenously in suitable priming doses, followed by a sustaining infusion of each administered intravenously at a constant rate of 4 to $5 \mathrm{ml}$. per minute. Urine was collected in periods averaging 20 minutes each. With each collection the bladder was washed with distilled water followed by air. In 14 of the studies only the clearances of endogenous creatinine were determined.

Paraminohippurate was measured by the method of Bratton and Marshall (3), inulin by the method of Higashi and Peters (4), and creatinine by the method of Bonsnes and Taussky (5). Sodium and potassium were determined with the Beckman flame photometer.

Usually the initial observations were made in the lateral recumbent position. One hour after starting oral hydration and one-half hour before starting the first collection period the patient was limited to lying on her side. Two to three collections were made while she was lying in the lateral recumbent position and then the subject was turned on her back, the head being maintained at the same level. After three to six collection periods on her back she was returned to her side for two or three periods. In a few studies the opposite approach was used, starting with the patient on her back, then turning her on her side, and finally returning to her back.

In studying two normal near-term pregnant and two normal post-hysterectomy subjects blood pressure cuffs were applied loosely high on each thigh prior to study. Initially, two to three observations were made with the patient in the supine position and then she was turned on her side. After three to four periods on the side the blood pressure cuffs were inflated and their pressures maintained at 40 to $60 \mathrm{~mm}$. Hg. After three to four periods the pressure was released and with the patient still on her side two or three more collections were made.

Brachial arterial blood pressures determined with a cuff and the radial pulse rates were measured at the time of administration of water and at the end of each urine collection period. Care was taken to maintain the comfort of the patient and to minimize apprehension.

\section{OBSERVATIONS}

Urine flow in the lateral recumbent position ranged from 4 to $12 \mathrm{ml}$. per minute. In this posi- 
TABLE I

Near-term non-toxemic pregnant women-The per cent change in renal function when supine compared to bying on the side

\begin{tabular}{|c|c|c|c|c|c|}
\hline Patient & $\begin{array}{c}\text { Urine } \\
\text { flow } \\
\% \\
\text { Change }\end{array}$ & $\begin{array}{c}\text { Na/Min. } \\
\% \\
\text { Change }\end{array}$ & $\begin{array}{l}\text { K/Min. } \\
\text { \% } \\
\text { Change }\end{array}$ & $\begin{array}{c}\text { RPF } \\
\text { \% } \\
\text { Change }\end{array}$ & $\begin{array}{c}\text { GFR } \\
\text { \% } \\
\text { Change }\end{array}$ \\
\hline $\begin{array}{l}\text { H. J. } \\
\text { L. M. } \\
\text { S. M. } \\
\text { M. B. } \\
\text { J. W. } \\
\text { P. M. } \\
\text { N. T. } \dagger \\
\text { N. S. } \\
\text { A. M. } \\
\text { B. J. f(1) } \\
\text { (2)\& }\end{array}$ & $\begin{array}{l}-31 \\
-63 \\
-18 \\
-45 \\
-20 \\
-37 \\
-62 \\
-54 \\
-36 \\
-68 \\
-64\end{array}$ & $\begin{array}{l}-27 \\
-68 \\
-35 \\
-36 \\
-19 \\
-44 \\
-54 \\
-45 \\
-50 \\
-62 \\
-60\end{array}$ & $\begin{array}{l}-18 \\
-22 \\
-6 \\
-4 \\
0 \\
-18 \\
- \\
-40 \\
-21 \\
-16\end{array}$ & $\begin{array}{l}+8 \\
-4 \\
-8 \\
- \\
- \\
- \\
-28 \\
-24\end{array}$ & $\begin{array}{l}+1 \\
-14^{*} \\
+3 \\
-6 \\
-2^{*} \\
-8^{*} \\
- \\
- \\
-6^{*} \\
-23 \\
-18\end{array}$ \\
\hline Average & $-43 \%$ & $-44 \%$ & $-16 \%$ & $-7.5 \%$ & $-6.5 \%$ \\
\hline
\end{tabular}

* Endogenous creatinine clearance.

+ Twins.

‡ Thirty-six weeks' pregnant plus large uterine fibromyomas.

8 Bilateral ureteral catheters inserted beyond brim of pelvis.

tion the excretion of sodium and potassium per minute ranged from 58 to 240 microequivalents and 46 to 198 microequivalents, respectively, while RPF and GFR ranged from 325 to $740 \mathrm{ml}$. and 84 to $165 \mathrm{ml}$., respectively. The lower values usually occurred in the preeclamptic group. The blood pressure and pulse rate were not significantly different in the two positions.

TABLE II

Near-term preeclamptic pregnant women-The per cent change in renal function when supine compared to lying on the side

\begin{tabular}{|c|c|c|c|c|c|}
\hline Patient & $\begin{array}{c}\text { Urine } \\
\text { flow } \\
\% \\
\text { Change }\end{array}$ & $\begin{array}{c}\mathrm{Na} / \mathrm{Min} . \\
\% \\
\text { Change }\end{array}$ & $\begin{array}{l}\text { K/Min. } \\
\text { \% } \\
\text { Change }\end{array}$ & $\begin{array}{c}\text { RPF } \\
\text { \% } \\
\text { Change }\end{array}$ & $\begin{array}{c}\text { GFR } \\
\text { \% } \\
\text { Change }\end{array}$ \\
\hline $\begin{array}{l}\text { D. J. } \\
\text { L. B. }{ }^{*(1)}(2) \\
\text { J. V. (1) } \\
\text { K. M. } \\
\text { V. P. } \\
\text { E. H. } \\
\text { K. S. }{ }^{* \pm(1)}(2) \\
\text { M. W. }\end{array}$ & $\begin{array}{l}-31 \\
-48 \\
+5 \\
-36 \\
-73 \\
-6 \\
-66 \\
-31 \\
-44 \\
-81 \\
-69 \\
-63 \\
-43\end{array}$ & $\begin{array}{l}-31 \\
-40 \\
+2 \\
-30 \\
-70 \\
-10 \\
-56 \\
-29 \\
-34 \\
-63 \\
-48 \\
-67 \\
-40\end{array}$ & $\begin{array}{l}-15 \\
-32 \\
+5 \\
- \\
-12 \\
-28 \\
-8 \\
-18 \\
-2 \\
+2 \\
-28\end{array}$ & $\begin{array}{l}-14 \\
-22 \\
+4 \\
-18 \\
-4 \\
+2 \\
- \\
-14 \\
-39 \\
-36 \\
-34 \\
-\end{array}$ & $\begin{array}{l}-9 \\
-23 \\
-2 \\
-16 \\
-3 \\
-3 \\
-12 \dagger \\
+3 \dagger \\
-8 \\
-33 \\
-30 \\
-27 \\
-18 \dagger\end{array}$ \\
\hline verage & $-44^{\circ}$ & -390 & -150 & $-15 \%$ & $-11 \%$ \\
\hline
\end{tabular}

* About one week intervals.

$\dagger$ Endogenous creatinine clearance.

t Twins.

Bilateral ureteral catheters inserted beyond brim of pelvis.
In 22 of the 24 studies on 18 near-term pregnant women the supine position compared to the lateral recumbent was associated with moderate to marked and nearly parallel reductions in the rate of urine flow and sodium excretion (Table I, II). The excretion of potassium, in general, was moderately decreased but the changes were much more variable than for sodium and water. Little difference was found in the effect of the supin: position on RPF, GFR, sodium excretion, or urine flow between the normal and toxemic pregnant groups. The responses of RPF and GFR to the supine position showed considerable variation from patient to patient. Three patterns were noted. In some there was an appreciable decrease in RPF and GFR which was maintained throughout the supine periods. A typical example is shown in Figure 1. In others there was an initial drop in RPF and GFR followed by recovery even though the supine position was maintained and sodium and water excretion continued to be depressed. A third group, while developing significant decreases in sodium and water excretion during the supine periods, showed no real change in RPF or GFR.

The decreases in water and sodium excretion while lying on the back were usually not immedi-

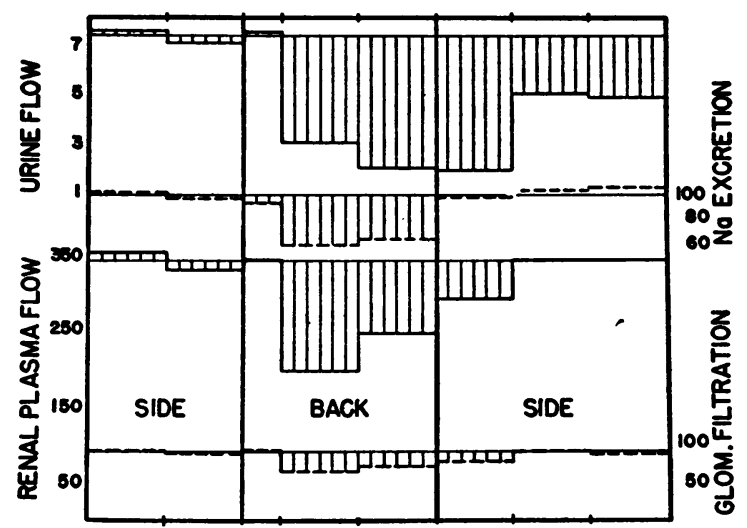

Fig. 1. The Effect of the Supine Position on Urine Flow, Sodium Excretion, Efrective Renal Plasma Flow and Glomerular Filtration Rate in the Near-Term Subject K. S. with Preeclampsia AND TwINS

Urine flow, renal plasma flow, and glomerular filtration rate are expressed as $\mathrm{ml}$. per Min.; sodium excretion is expressed as microequivalents per minute. The total time in minutes for each position, side, back, and again side, were 42,55 , and 63 minutes, respectively. 
TABLE III

Non-pregnant women with large abdominal neoplasmsThe per cent change in renal function when supine compared to lying on the side

\begin{tabular}{lcccc}
\hline \hline Patient & $\begin{array}{c}\text { Urine flow } \\
\text { \% Change }\end{array}$ & $\begin{array}{c}\text { Na/Min. } \\
\% \text { Change }\end{array}$ & $\begin{array}{c}\text { K/Min. } \\
\% \text { Change }\end{array}$ & $\begin{array}{c}\text { GFR* } \\
\text { \% Change }\end{array}$ \\
\hline H.S. $\dagger$ & -41 & -34 & -11 & -14 \\
B. J. $\neq$ & -66 & -51 & -25 & -20 \\
\hline Average & $-53 \%$ & $-42 \%$ & $-18 \%$ & $-17 \%$
\end{tabular}

* Endogenous creatinine clearance.

† Ovarian serous cystadenocarcinoma.

$\ddagger$ Large uterine fibromyomas.

ately maximal but became so only after 10 to 20 minutes in the supine position; when the patient again was placed on her side, recovery frequently was similarly delayed. Figure 1 demonstrates a typical response.

In the two patients in whom no reduction in RPF, GFR, sodium excretion, or urine flow was noted while supine, the studies were carried out more than once. One (L. B., Table II) on two other occasions, one week before and one week after, showed significant decreases in the supine position. The other (J. V., Table II), when placed in the supine position, demonstrated a marked decrease in water and sodium excretion the first time studied but 24 hours later failed to show a similar response.

Positional alteration from side to back in the two women with large abdominal neoplasms arising from the pelvis (Table III) produced changes in urine flow, sodium and potassium excretion and GFR as estimated by the clearance of endogenous creatinine comparable to those seen in the near-

TABLE IV

Postpartum or post-hysterectomy women-The per cent change in renal function when supine compared to lying on the side

\begin{tabular}{|c|c|c|c|c|c|}
\hline Patient & $\begin{array}{l}\text { Urine } \\
\text { flow } \\
\% \% \\
\text { Change }\end{array}$ & $\begin{array}{c}\text { Na/Min. } \\
\% \\
\text { Change }\end{array}$ & $\begin{array}{l}\text { K/Min. } \\
\text { \% } \\
\text { Change }\end{array}$ & $\begin{array}{c}\text { RPF } \\
\text { \% } \\
\text { Change }\end{array}$ & $\begin{array}{c}\text { GFR } \\
\% \% \\
\text { Change }\end{array}$ \\
\hline 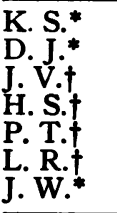 & $\begin{array}{l}+8 \\
+2 \\
-30 \\
-4 \\
-10 \\
-2 \\
-12\end{array}$ & $\begin{array}{l}+5 \\
+5 \\
-10 \\
+3 \\
-14 \\
-5 \\
-8\end{array}$ & $\begin{array}{r}-2 \\
-13 \\
-6 \\
+7 \\
+3 \\
+3 \\
+1\end{array}$ & $\begin{array}{l}+3 \\
+1 \\
= \\
= \\
=\end{array}$ & $\begin{array}{l}-2 \\
+4 \\
-3 \ddagger \\
-3 \ddagger \\
-8 \ddagger \\
-4 \ddagger \\
-3 \ddagger\end{array}$ \\
\hline Average & $-7 \%$ & $-3 \%$ & $-2 \%$ & $+2 \%$ & $-3 \%$ \\
\hline
\end{tabular}

* Seven or more days postpartum.

$\dagger$ Nine or more days post-hysterectomy.

‡ Endogenous creatinine clearance. term pregnant subjects. In the seven patients who either had been delivered or who had undergone hysterectomy 7 to 10 days before study very little change was noted in these components of renal function when the recumbent subjects were turned from the side to the back (Table IV).

Two subjects (B. J., Table I, and K. S., Table II) showed functional alterations in the supine position almost identical to those previously observed in each, although ureteral compression by the pregnant uterus had been made virtually impossible by the presence of large-bore heavy-walled ureteral catheters inserted bilaterally into the ureters well beyond the level of the brim of the pelvis.

Sodium and water excretion while supine was compared to the excretion during femoral venous compression in the lateral recumbent position. Four women, two near-term pregnant and two non-pregnant, were studied. In the recumbent pregnant group the shift from the back to the side resulted in an appreciable increase in urine flow and sodium excretion but in the non-pregnant subjects the same change of position produced no change. While remaining in the lateral recumbent position, blood pressure cuffs high on each thigh were inflated to subdiastolic pressures of

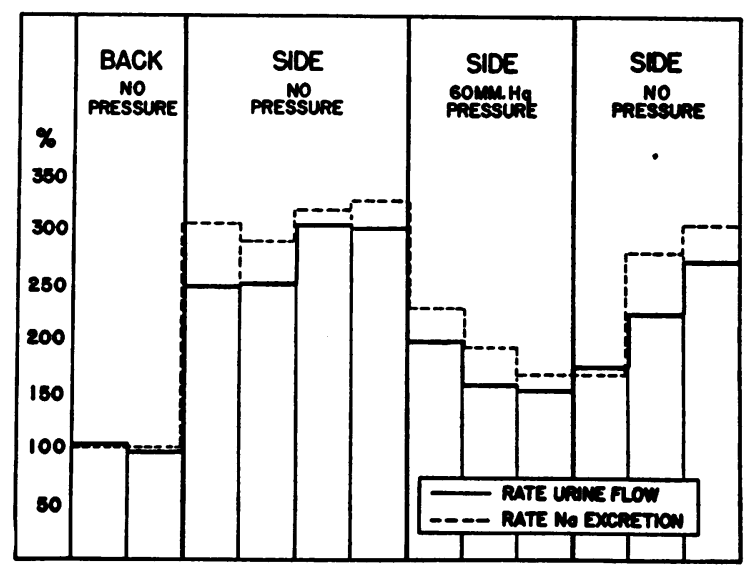

Fig. 2. The Percentage Change in Sodium and Water Excretion in a Near-Term Pregnant Subject L. M. When Turned frox Lying on Her Back to Lying on Her Side and Then With and Without Blood Pressure Cuffs High on Each Thigh Inflated To 60 MM. Hg

The total time in each of the four procedures was 39, 74, 55, and 56 minutes. Urine flow and sodium excretion while on the back averaged $1.53 \mathrm{ml}$. and 43 microequivalents per minute. 
40 to $60 \mathrm{~mm}$. Hg. In all women, pregnant and non-pregnant, this was followed by a significant fall in sodium and water excretion. Release of the cuff pressure resulted in recovery. The observed changes in one near-term pregnant woman are shown in Figure 2.

\section{DISCUSSION}

There are many possibilities regarding the genesis of these marked reductions in urine flow and sodium excretion observed in the supine subject with a large pregnant uterus or with a large abdominal tumor arising from the pelvis. Among them are compression of the iliac veins at the pelvic brim, compression of the inferior vena cava either below or above the level of the renal veins or both, compression of the extrarenal portions of the renal veins, or compression of the kidney itself. Not encountered in any of these subjects and therefore excluded as a cause was the so-called supine hypotensive syndrome, in which merely positioning a woman late in pregnancy on her back results in arterial hypotension (6). Any ureteral compression at the brim of the pelvis produced by the large pregnant uterus did not appear to cause the reductions in sodium and water excretion in the supine position since in two cases the presence of large-bore heavy-walled ureteral catheters failed to inhibit the effects of the supine position on the excretion of sodium and water.

Bradley and Bradley ( 7 ) observed that the elevation of intraabdominal pressure by means of an inflated balloon strapped to the abdomen of normal subjects produced changes in renal function quite similar to those found in these supine nearterm pregnant women and women with large abdominal tumors of pelvic origin. They observed a sharp fall in urine flow accompanied by somewhat more variable decreases in RPF and GFR. Farber, Becker, and Eichna similarly studied renal function before and during congestion of the inferior vena cava using a venous catheter with an attached inflatable balloon (8). Following inflation of the balloon there were changes in renal function similar to those noted by Bradley and Bradley and those observed in the supine women. The degree of change was less marked if the venal caval congestion was produced below the level of the renal veins than if it was created above that level. Other investigators, by applying tourniquets to the thighs at subdiastolic pressures to cause femoral venous compression, produced comparable changes in the excretion of sodium and water $(9,10)$.

Femoral venous pressures have been observed in non-pregnant subjects to be only slightly increased in the supine position whereas in term pregnant individuals in the supine position they are almost twice as great as in the lateral recumbent position (6). The similarities in the changes in renal function noted in the present experiments in supine subjects with either large pregnant uteri or with large pelvic tumors to the changes produced by the compression of either the inferior vena cava or the femoral veins suggest that the decreases in sodium and water excretion in the supine position may also result from comparable venous compression.

The extent of the venous pressure elevation above the femoral veins in supine pregnant women does not appear to have been investigated. Whether this position results in venous pressure elevations only in the tributaries distal to the inferior vena cava at and below the level of the brim of the pelvis or whether there is also augmentation of venous pressure in the vena cava and renal veins when supine is not known. Studies in progress include the measurement of pressures in the supine position at various levels of the inferior vena cava by means of venous catheters. It is hoped that by such studies it will be possible to account for the occasional absence of reduction in water and sodium excretion in near-term pregnant women in the supine position, for it is conceivable that the degree of venous compression by the uterus and its contents may vary not only from subject to subject but also may vary in the same subject at different times depending on the anatomical relationship of the fetus and uterus to the venous return system.

\section{SUMMARY}

Shifting near-term pregnant women from lying on their sides to lying on their backs resulted in a considerable decrease in the rate of excretion of water and sodium. The excretion of potassium and effective renal plasma flow and glomerular filtration rates usually were not as markedly affected. 
The renal response to the supine position was not peculiar to pregnancy for similar changes were observed in women with large abdominal neoplasms pelvic in origin.

The mechanism by which these changes were produced remains somewhat obscure but appears to involve venous compression rather than ureteral obstruction.

\section{ACKNOWLEDGMENTS}

The authors wish to thank Dr. Lester Persky and Misses Helen Karlovec and Ruth Wagner for their assistance during this study.

\section{REFERENCES}

1. Walker, E. W., McManus, M., and Janney, J. C., Kidney function in pregnancy. II. Effect of posture on diuresis. Proc. Soc. Exper. Biol. \& Med., 1933-34, 31, 392.

2. Hendricks, C. H., and Barnes, A. C., The effect of the supine position on urinary output in pregnancy. Am. J. Obst. \& Gynec. In press.

3. Bratton, A. C., and Marshall, E. K., Jr., A new coupling component for sulfanilamide determination. J. Biol. Chem., 1939, 128, 537.
4. Higashi, A., and Peters, L., A rapid colorimetric method for the determination of inulin in plasma and urine. J. Lab. \& Clin. Med., 1950, 35, 475.

5. Bonsnes, R. W., and Taussky, H. H., On the colorimetric determination of creatinine by the Jaffe reaction. J. Biol. Chem., 1945, 158, 581.

6. Howard, B. K., Goodson, J. H., and Mengert, W. F., Supine hypotensive syndrome in late pregnancy. Obst. \& Gynec., 1953, 1, 371.

7. Bradley, S. E., and Bradley, G. P., The effect of increased intra-abdominal pressure on renal function in man. J. Clin. Invest., 1947, 26, 1010.

8. Farber, S. J., Becker, W. H., and Eichna, L. W., Electrolyte and water excretions and renal hemodynamics during induced congestion of the superior and inferior vena cava of man. J. Clin. Invest., 1953, 32, 1145.

9. Fitzhugh, F. W., McWhorter, R. L., Estes, E. H., Jr., Warren, J. V., and Merrill, A. J., The effect of application of tourniquets to the legs on cardiac output and renal function in normal human subjects. J. Clin. Invest., 1953, 32, 1163.

10. Wilkins, R. W., Tinsley, C. M., Culbertson, J. W. Burrows, B. A., Judson, W. E., and Burnett, C. $H$., The effects of venous congestion of the limbs upon renal clearances and the excretion of water and salt. I. Studies in normal subjects and in hypertensive patients before and after splanchnicectomy. J. Clin. Invest., 1953, 32, 1101. 